\title{
Idiopathic inflammatory myopathy comorbid with Sturge-Weber syndrome: a case report
}

\author{
Li Deng ${ }^{1 \dagger}$, Dongmei Wang $^{2 \dagger}$, Ni Ruan ${ }^{1}$ and Ping Fu ${ }^{*}$
}

\begin{abstract}
Background: Sturge-Weber syndrome (SWS) is a rare and sporadic congenital neurocutaneous disorder, that is characterized by facial venous capillary malformation (port-wine birthmark), leptomeningeal venous malformation (angiomatosis), glaucoma, and neurologic problems. SWS can comorbid with other disorders in some patients, however, muscular abnormalities have still not been reported in patients with SWS.

Case presentation: A forty-one-year-old Chinese female who had left side port-wine stain, ipsilateral glaucoma, and hypothyroidism was included in the present study. The neurocutaneous and endocrine symptoms were consistent with the SWS diagnostic criteria. Meanwhile, the patient had progressive weakness on her both arms and legs, dramatically elevated creatine kinase (CK) and myoglobin levels, and elevated antinuclear and anti-Ro52 antibodies. Intravenous methylprednisolone (MP) (80 mg/d), methotrexate, and intravenous cyclophosphamide were administrated and the weakness of the patient was gradually relieved with normal serum CK level.
\end{abstract}

Conclusions: We reported the first case of SWS comorbid with inflammatory myopathy. The underlying mechanism for SWS and idiopathic inflammatory myopathy is still not clear, and further researches need to be conducted to deeply explore the mentioned mechanism.

Keywords: Sturge-Weber syndrome (SWS), Idiopathic inflammatory myopathy (IIM)

\section{Background}

Sturge-Weber syndrome (SWS) is a rare and sporadic congenital neurocutaneous disorder, which is characterized by facial venous capillary malformation (port-wine birthmark), leptomeningeal venous malformation (angiomatosis), and glaucoma and neurologic problems (e.g., seizures, stroke-like episodes, mental retardation, migraine, and hemiparesis) [1]. Recently, a somatic mutation of the guanine nucleotide-binding protein $\mathrm{G}(\mathrm{q})$ subunit alpha (GNAQ) gene has been described as a cause of the disease [2]. The clinical presentation and prognosis of SWS is highly variable between patients, ranging from no or minimal

\footnotetext{
* Correspondence: 1756047267@qq.com

${ }^{\dagger}$ Li Deng and Dongmei Wang contributed equally to this work.

'Department of Rheumatology and Clinical Immunology, The Second Affiliated Hospital of Kunming Medical University, 374 Dianmian Avenue Wuhua District, Kunming 650101, Yunnan, China

Full list of author information is available at the end of the article
}

neurological signs to severe neurologic deficits with recurrent seizures, hemiparesis, visual field deficit, and attention and learning disability [3].

Idiopathic inflammatory myopathies (IIM), collectively known as myositis, are a heterogeneous group of rare conditions that affect multiple organs apart from muscles [4]. The five most recognized types of IIM include dermatomyositis, immune-mediated necrotizing myopathy, overlap myositis (including antisynthetase syndrome), sporadic inclusion-body myositis, and polymyositis [5]. Patients with IIM usually present with symmetrical and proximal limb weakness which develops over weeks or months [6]. Some extramuscular manifestations including arthralgia, non-erosive arthritis, cardiac involvement, pulmonary and gastrointestinal complications have commonly existed [7-9]. Muscle biopsy is very reliable to facilitate the diagnosis, that is conventional among $85 \%$ of the patients [10].

(c) The Author(s). 2019 Open Access This article is distributed under the terms of the Creative Commons Attribution 4.0 International License (http://creativecommons.org/licenses/by/4.0/), which permits unrestricted use, distribution, and reproduction in any medium, provided you give appropriate credit to the original author(s) and the source, provide a link to the Creative Commons license, and indicate if changes were made. The Creative Commons Public Domain Dedication waiver (http://creativecommons.org/publicdomain/zero/1.0/) applies to the data made available in this article, unless otherwise stated. 
Herein, we presented a case of SWS with clinical diagnosis of IIM, and it is the first case that SWS and IIM are observed together. The patient recovered with steroids and immunosuppressant.

\section{Case presentation}

A forty-one-year old female admitted to our hospital with chief complain of Raynaud's phenomenon for 2 years, and weakness of four extremities for about 2 months. She had morning stiffness of both hands and the symptoms were relieved after $20-30 \mathrm{~min}$ of repeated rubbing. No joint pain, fever, oral ulceration, alopecia and rash were noticed. In addition, 2 months before beginning the admission, the patient felt weakness on her both arms and legs, and the weakness aggravated progressively. Difficulties in squatting or standing up, as well as hair combination were noticed. She also complained about muscle tenderness without any difficulty in breathing or swallowing. She was diagnosed as hypothyroid myopathy in a local hospital and levothyroxine was taken. However, her weakness was not improved, accordingly, she was transferred to our department.

The patient's past medical history was remarkable for left glaucoma with retinal detachment and impaired visual sight in 2015. Besides, she was diagnosed as SWS since childhood. She was also diagnosed as hypothyroidism, and regular levothyroxine replacement was given for several years as well.

Physical examination revealed that the vital sign is stable. $12 \mathrm{~cm} \times 12 \mathrm{~cm}$ red patches were visible on her left side, and the boundary was unclear as well. Thyroid nodules and swelling were not palpated. Breathing sounds in both lungs were clear. Proximal muscle strength of her both arms was in level-4 (the UK Medical Research Council criteria), and strength of both proximal legs was in level-3 as well. The distal strengths of her arms and legs were normal, and muscle tenderness was quite obvious in her both arms and legs. Other neurological examinations were not significant.

Laboratory examinations revealed positive anti-nuclear antibody with titer of 1:320 (particle pattern), positive anti-recombinant RO-52 (+++), positive weakly anti-nucleosome antibody $(+)$, and negative anti-neutrophil cytoplasmic antibodies (ANCA). Level of serum creatine kinase (CK) was 11,183 U/L (normal range: 26-140), and myoglobin was 1916 ng/ml (normal range: 25-58). Other chemical examinations revealed that alanine aminotransferase (ALT), aspartate aminotransferase (AST), and lactate dehydrogenase (LDH) were elevated. Thyroid function was normal with $278 \mathrm{IU} / \mathrm{ml}$ (normal range:0-115) of elevated anti- thyroglobulin (TG). Electromyography (EMG) showed typical myopathic findings with predominantly proximal muscle weakness. Cranial magnetic resonance imaging (MRI) showed increased anterior chamber of left eye, skin thickening of left facial and abnormal signals of interior wall of left eye, as well as upper and lower recuts. Intracranial brain parenchyma was normal and magnetic resonance angiography (MRA) was not remarkable as well.

Inflammatory myopathy was diagnosed based on the clinical features and laboratory results. Intravenous methylprednisolone (MP $(80 \mathrm{mg} / \mathrm{d})$ was administrated and methotrexate $(10 \mathrm{mg} /$ week) was intramuscularly injected. The patient's muscle strength gradually improved, and CK dramatically decreased to $2800 \mathrm{U} / \mathrm{L}$. After 2 weeks, methylprednisolone was gradually tapered to $40 \mathrm{mg} / \mathrm{d}$. As the CK was quite high, intravenous cyclophosphamide was added with a total amount of $6 \mathrm{~g}$.

The patient was discharged with oral MP tapering and methotrexate (MTX) (7.5 mg/week) for maintenance. She was regularly followed-up at our clinic as well. For about half a year, the muscle strength of her arms and legs returned to normal status, and CK was also within normal range.

\section{Discussion and conclusions}

SWS is rare with estimated frequency between 1:20,000 to 1: 50,000 [11]. The clinical features are facial port-wine stains (PWSs) in the V1 distribution (ophthalmic division) of the trigeminal nerve, ipsilateral glaucoma, vascular eye abnormalities, and intracranial occipital-leptomeningeal angiomata. SWS is a disease which affect multiple systems. It is important for neurologists to be aware of other medical issues including the endocrine, psychiatric, ophthalmologic manifestations which can cause and impact the neurologic status of the patients. Recently, some of the clinical features have been reported [1].

The majority of patients with neurologic involvement have seizures in infancy. Besides, neurological deficits can be gradually acquired over a long time. Cognitive impairments are quite common in patients, however, range greatly from minimal attention or mild learning problem to very severe cognitive impairment. Headache and migraines are commonly reported in SWS [1]. In recent years, SWS comorbid with central hypothyroidism has been reported [12], however, the etiology of central hypothyroidism is not clearly elucidated. The possible cause could be the disturbance of hypothalamic-pituitary axis.

In this case, the patient was with typical facial port-wine stain in the V1 distribution, in which ipsilateral glaucoma confirms the diagnosis of SWS. Hypothyroidism also supports the diagnosis of SWS though a primary thyroid function test was lost, and made it difficult to differentiate the central from secondary hypothyroidism. The patient had no prominent brain involvement, history of seizures, headache, or cognitive impairment. The cranial MRI and MRA revealed no abnormality as well. 
An impressive feature of this case was that the patient comorbid with severe muscle weakness, dramatically elevated CK and myopathic EMG changes, and elevated autoantibodies as well. The weakness of muscle was alleviated with steroids and immunosuppressant. The differential diagnosis includes myopathy caused by hypothyroidism and other congenital muscle diseases. As no muscle biopsy was conducted, the clinical course, treatment, and the clinical follow-up result of the patient highly suggest the diagnosis of inflammatory myopathy. The diagnosis was confirmed by 2017 European League Against Rheumatism/ American College of Rheumatology classification criteria. This patient's score was 7.6 and the classification was definite IIM with $91 \%$ probability [13]. To our knowledge, no SWS comorbid with IIM has been reported, and the relationship between SWS and IIM is still not clear.

A case of SWS with episodes of rhabdomyolysis has been reported in a Chinese girl and the pathology confirmed the diagnosis of lipid metabolic myopathy [14]. The suggested mechanism is that GNAQ mutation in somatic cells is closely related to dermatology disease. Central nervous system (CNS), musculoskeletal system, eyes, and teeth are typically involved in neurocutaneous disorders [15]. Although muscular disorders have not been found in SWS [16], in terms of tissue development, SWS and muscles originate from the same germ layer [14].

In our study, it was revealed that the somatic GNAQ mutations may be associated with the pathways of IIM. However, no genetic test for GNAQ or muscle biopsy was conducted because of limited financial budget.

We presented a case of SWS comorbid with inflammatory myopathy. The relationship between SWS and IIM is still unclear, and further research is required. In addition, a clinician should consider IIM when a SWS patient has muscle weakness, which may be misdiagnosed as stroke-like episodes of SWS.

\section{Abbreviations}

CK: Creatine kinase; EMG: Electromyography; GNAQ: Guanine nucleotidebinding protein $\mathrm{G}(\mathrm{q})$ subunit alpha; IIM: Idiopathic inflammatory myopathy; MP: Methylprednisolone; MRA: Magnetic resonance angiography; MRI: Magnetic resonance imaging; SWS: Sturge-Weber syndrome

\section{Acknowledgements}

We sincerely appreciate the generosity of our patient for approving publication of this case report.

\section{Funding}

We receive no funding support.

\section{Availability of data and materials}

All data generated or analyzed during this study are included in this published article.

\section{Authors' contributions}

LD and NR treated the patient. DW and PF draft the manuscript. NR collected the clinical data. PF critically reviewed the clinical data and conducted data analysis. All authors participated in the discussion and preparation of the manuscript. All authors read and approved the final manuscript.

\section{Ethics approval and consent to participate}

This case report has been approved by the Ethics Board of Kunming Medical University. A written informed consent to participate from the patient and her family members was obtained.

\section{Consent for publication}

Written informed consents were obtained from the patient for publication of this case report and any accompanying images. A copy of the written consent is available for review by the Editor of this journal.

\section{Competing interests}

The authors declare that they have no competing interests.

\section{Publisher's Note}

Springer Nature remains neutral with regard to jurisdictional claims in published maps and institutional affiliations.

\section{Author details}

'Department of Rheumatology and Clinical Immunology, The Second Affiliated Hospital of Kunming Medical University, 374 Dianmian Avenue Wuhua District, Kunming 650101, Yunnan, China. '2Department of Neurology, Nanfang Hospital, Southern Medical University, Guangzhou 510515,

Guangdong, China.

Received: 31 July 2018 Accepted: 15 April 2019

Published online: 03 May 2019

\section{References}

1. Comi AM. Presentation, diagnosis, pathophysiology, and treatment of the neurological features of Sturge-weber syndrome. Neurologist. 2011;17(4): 179-84.

2. Shirley MD, Tang H, Gallione CJ, Baugher JD, Frelin LP, Cohen B, North PE, Marchuk DA, Comi AM, Pevsner J. Sturge-weber syndrome and port-wine stains caused by somatic mutation in GNAQ. N Engl J Med. 2013;368(21): 1971-9.

3. Lo W, Marchuk DA, Ball KL, Juhasz C, Jordan LC, Ewen JB, Comi A, Brain Vascular Malformation Consortium National Sturge-Weber Syndrome W. Updates and future horizons on the understanding, diagnosis, and treatment of Sturge-weber syndrome brain involvement. Dev Med Child Neurol. 2012;54(3):214-23.

4. Schmidt J. Current classification and Management of Inflammatory Myopathies. J Neuromuscul Dis. 2018;5(2):109-29.

5. Selva-O'Callaghan A, Pinal-Fernandez I, Trallero-Araguas E, Milisenda JC, Grau-Junyent JM, Mammen AL. Classification and management of adult inflammatory myopathies. Lancet Neurol. 2018;17(9):816-28.

6. Harris-Love MO, Shrader JA, Koziol D, Pahlajani N, Jain M, Smith M, Cintas HL, McGarvey CL, James-Newton L, Pokrovnichka A, et al. Distribution and severity of weakness among patients with polymyositis, dermatomyositis and juvenile dermatomyositis. Rheumatology (Oxford). 2009;48(2):134-9.

7. Fathi M, Vikgren J, Boijsen M, Tylen U, Jorfeldt L, Tornling G, Lundberg IE. Interstitial lung disease in polymyositis and dermatomyositis: longitudinal evaluation by pulmonary function and radiology. Arthritis Rheum. 2008; 59(5):677-85.

8. Hallowell RW, Ascherman DP, Danoff SK. Pulmonary manifestations of polymyositis/dermatomyositis. Semin Respir Crit Care Med. 2014;35(2):239-48.

9. Spiera R, Kagen L. Extramuscular manifestations in idiopathic inflammatory myopathies. Curr Opin Rheumatol. 1998:10(6):556-61.

10. laccarino L, Gatto M, Bettio S, Caso F, Rampudda M, Zen M, Ghirardello A, Punzi L, Doria A. Overlap connective tissue disease syndromes. Autoimmun Rev. 2013;12(3):363-73

11. Comi AM. Update on Sturge-weber syndrome: diagnosis, treatment, quantitative measures, and controversies. Lymphat Res Biol. 2007;5(4):257-64

12. Comi AM, Bellamkonda S, Ferenc LM, Cohen BA, Germain-Lee EL. Central hypothyroidism and Sturge-weber syndrome. Pediatr Neurol. 2008;39(1):58-62.

13. Lundberg IE, Tjarnlund $A$, Bottai M, Werth VP, Pilkington C, Visser M Alfredsson L, Amato AA, Barohn RJ, Liang MH, et al. 2017 European league against rheumatism/American College of Rheumatology classification criteria for adult and juvenile idiopathic inflammatory 
myopathies and their major subgroups. Ann Rheum Dis. 2017;76(12): 1955-64.

14. Zhu M, Li X, Zhou M, Wan H, Wu Y, Hong D. Sturge-weber syndrome coexisting with episodes of rhabdomyolysis. BMC Neurol. 2013;13:169.

15. Nabbout R, Juhasz C. Sturge-Weber syndrome. Handb Clin Neurol. 2013;111: 315-21.

16. Rahman M, Rahman S, Rahman M, Akhter S, Kawser C. Overlapping of Sturge Weber syndrome and Klippel Trenaunay Weber syndrome. Mymensingh Med J. 2008;17(1):78-81

Ready to submit your research? Choose BMC and benefit from:

- fast, convenient online submission

- thorough peer review by experienced researchers in your field

- rapid publication on acceptance

- support for research data, including large and complex data types

- gold Open Access which fosters wider collaboration and increased citations

- maximum visibility for your research: over $100 \mathrm{M}$ website views per year

At $B M C$, research is always in progress.

Learn more biomedcentral.com/submissions 